\title{
СОВРЕМЕННЫЕ ПОДХОДЫ ПО ОБЕСПЕЧЕНИЮ СОХРАННОСТИ ГРУЗОВ ПРИ ПЕРЕВОЗКЕ ЖЕЛЕЗНОДОРОЖНЫМ ТРАНСПОРТОМ
}

\author{
(ㄱ Д. В. Ломотько, Я. В. Запара, В. А. Лютый
}

На основе проведенного исследования нами предложены ряд мер по повымению качества сохранности грузов при перевозке железнодорожным транспортом. Оченен экономический эффект некоторых из них. Рассмотрены правовые отношения железных дорог и грузовладельцев в аспекте ответственности за несохранность и предложена модель управления страховыми рисками несохранности при перевозке Ключевые слова: грузовые перевозки, несохранность грузов, военизированная охрана, экономический эффект, страховые риски

On the basis of the study we have proposed a number of measures to improve the cargo protection during rail transportation. The economic impact of some of them is estimated. The legal relations of railways and cargo owners in terms of liability for failure to preserve are considered and proposed the management model of insurance risks of failure to preserve in transportation

Keywords: freight transportation, failure to cargo, militarized security, economic benefits, insurance risks

\section{1. Введение}

Сохранность грузов является одной из основных обязанностей железных дорог. Сохранность грузов в процессе перевозки непосредственно влияет на качество перевозки, она зависит как от железнодорожников, так и от грузовладельцев. Именно с работы грузовладельцев закладывается качество и сохранность перевозки. Грузовые перевозки на железнодорожном транспорте традиционно являются сферой наибольшей криминальной уязвимости. Несохранность грузов при транспортировке, в свою очередь, влечет за собой повреждения элементов инфраструктуры, нарушение определенных производственных циклов, прерывание цепочки хозяйственных связей между производителем и потребителем продукции, угрозу безопасности движения.

\section{2. Постановка проблемы}

В 2013 году значительно возросло количество краж и повреждений грузов, элементов подвижного состава и инфраструктуры, что привело к перерыву в движении поездов более чем на 30 мин. или отцепке подвижного состава от поездов в пути следования - в 98 случаях против 48 в 2012 году [1]. Негативная тенденция имеет место и требует введения дополнительных мер, направленных на повышение качества охраны грузов и элементов железнодорожной инфраструктуры. Основными причинами несохранности перевозок являются различные нарушения технологии и правил выполнения коммерческих операций, неудовлетворительная организация охраны грузов. Несоответствие наличия и состояния груза данным перевозочных документов может быть вызвано также указанием в документах превышенного веса груза вследствие неправильного взвешивания, неправильного подсчета мест при загрузке, выявления порчи или повреждения при принятии к перевозке и т. д.

Ежегодно железными дорогами Украины выполняется перевозка более 600 тыс. отправок, из которых каждая десятая отправка имеет коммерческую неисправность. Почти 40 \% всех коммерческих неисправностей обнаружено пунктами коммерческого осмотра поездов и вагонов (ПКО) на Одесской железной дороге, 28 \% на Донецкой и $20 \%$ на Приднепровской, остальные - 12 \% приходятся на Юго-Западную, Южную и Львовскую железные дорги [2].

Итак, вопрос сохранности грузов является актуальным и важным, в частности от качественной подготовки и охраны грузов при перевозке зависит безопасность движения и стабильная работа железнодорожного транспорта.

\section{3. Литературный обзор}

Мероприятия, направленные на сохранность перевозок и обеспечения безопасности движения всегда была приоритетным направлением в работе железных дорог. Этим занимались Данько Н. И., Кирпа Г. Н., Котенко А. Н., Мироненко В. К., Поляков А. О., Смехов А. А., Яновский П. А. и другие отечественные и зарубежные ученые. В последнее время, исследованиями в сфере сохранности грузов занимались такие ученые, как Данько Н. И., Запара В. М., Кузнецов М. М., Ломотько Д. В., Мироненко В. К., Пилипейко А. Н. и другие, однако в работах недостаточно было уделено внимания правовым аспектам сохранности перевозок и экономическому обоснованию предлагаемых мероприятий по повышению качества технологии охраны грузов $[3,4]$.

Украинскими железными дорогами проводится постоянная работа по повышению качества технологии охраны грузов и имущества железной дороги [5]. Однако, увеличение несанкционированных случаев вмешательства в деятельность железнодорожного транспорта, которые обусловлены криминогенными особенностями хищения грузов и имущества железных дорог, требует разработки и внедрения новых эффективных технических решений, направленных на предотвращение и предупреж- 
дение хищений грузов и элементов инфраструктуры. Существует определенный опыт стран СНГ и Европы по применению комплекса мер по повышению качества технологии охраны объектов железных дорог [6]. Так, эффективно ведется наблюдение за сохранностью имущества ОАО «РЖД» и грузами, при перевозке находящимися в парках железнодорожных станций. В Германии, Бельгии и других странах Европы для предотвращения краж на железных дорогах наряду с видеонаблюдением применяется ограждение парков станций, складов и т. д.

4. Исследование состояния обеспечения сохранности грузов при перевозке железнодоожным транспортом

Известно, что основными видами несохраности перевозимых грузов является: недостача (хищение, нехватка мест или веса груза), потеря, порча и повреждения. Как хищение учитывают недостачу груза, сопровождающуюся следующими обстоятельствами: срыв пломб, закруток; следы повреждений и подделки пломб; вскрытие тары грузовых мест; хищение деталей машин на открытом подвижном составе.

Железные дороги Украины пытаются решать эти вопросы с использованием как инновационных технологий, так и распространением опыта, учитывающим местные условия. Так, например, на Приднепровской железной дороге с целью защиты грузов, обеспечения их целостности при перевозках используется ряд действенных мер. На станциях Пятихатки-Стыковая, Чаплино, Павлоград-1 и других введены автоматизированные системы контроля за грузом и целостностью железнодорожных вагонов в движении. Участки, по которым чаще всего перевозят эти грузы, усиленно патрулируются совместными силами транспортной милиции и оперативных групп военизированной охраны (BОХР) Приднепровской железной дороги. Участки Пятихатки-Стыковая - Пятихатки и парки станций Пятихатки-Стыковая, Пятихатки, Запорожье-Левое охраняют частные (негосударственные) охранные предприятия.

За 2013 год на железных дорогах Украины раскрыто и предупреждено более 1,3 тыс. случаев неправомерных действий на сумму более 2 млн. грн. Большинство чищений раскрыто и предупреждено на Приднепровской железной дороге - 523, Донецкой 327 , Львовской - 182 и Юго-Западной - 157 случаев [7].

Проведен анализ несохранности грузов и по дирекциях железнодорожных перевозок. Так, на Днепропетровскую дирекцию отнесено 8,2 тыс. грн., или $11 \%$ общих убытков железной дороги по девяти отправками. По сравнению с тем же периодом прошлого года убытки снижены на 11,6 раза. Однако, в 3,5 раза возросли убытки по Криворожской дирекции: они составляют в отчетном периоде 47,7 тыс. грн. Из 35 станций дирекции, открытых для выполнения грузовых и коммерческих операций, убытки допущены на трех станциях. В частности, на станции Кривой Рог-Сортировочный - 43,9 тыс. грн. Указанная сумма отнесена на ответственность за нарушение правил приема к перевозке горношахтного оборудования и необеспечение условий для проезда стрелков ВОХР.

Исходя из проведенных исследований, реальными резервами повышения качества и надежности работы железнодорожного транспорта и улучшения использования подвижного состава в современных условиях является обеспечение на высоком уровне безопасности движения поездов, выполнение маневровых и погрузочно-разгрузочных работ, сохранности вагонов и грузов, повышение статической нагрузки вагона, а также всемерное повышение сохранности транспортируемых грузов. Железными дорогами перевозится большое количество широкой номенклатуры грузов, требующих особого внимания с точки зрения их сохранности в процессе перевозки.

Согласно [8], в случае нарушения обязательств, вытекающих из договора перевозки, стороны несут ответственность. Гражданскоправовая ответственность железной дороги основывается на общих принципах, закрепленных в статье 114 [8], где указано, что не предусмотренные договором перевозки расходы и убытки возмещению не подлежат. Если рассмотреть это с позиции грузовладельцев, то отдельные правовые основания перевозок не в полной степени отвечают требованиям привлекательности железных дорог.

С другой стороны, анализ схем погрузки показывает, что грузоподъемность вагонов используется лишь частично [9], а также имеют место нарушения требований условий нагрузки, направленных на обеспечение сохранности грузов. Нормативные потери следует считать случайным процессом уменьшения массы груза, повлиять на который возможно за счет организационнотехнических мероприятий. С правовой точки зрения, за нормативные потери ответственность не несет ни грузовладелец, ни железная дорога. Кроме того, по правилам ст. 130 [10] ответственность за случайную утрату несет грузовладелец. В случае просрочки в доставке груза, при его повреждении или потере ответственность несет сторона, просрочившая доставку, то есть железная дорога.

Для недопущения потерь грузовладельцами и железной дороги необходима разработка современных подходов по обеспечению сохранности грузов. Только проведение комплексных мероприятий в перевозочном процессе позволит существенно снизить существующие случаи несохранности грузов. Для этого необходимо продолжать оснащение станций массовой погрузки и ПКО инновационными техническими средствами контроля, добиваясь от грузоотправителей беспреословного выполнения требований Правил перевозок по обеспечению сохранности грузов; установить постоянный усиленный контроль за продвижением и охраной грузовых поездов с грузами, которые больше всего интересуют расхитителей, а также 
внедрять другие действенные меры совместно с ВОХР и правоохранителями.

Предлагаются технические, технологические и организационные меры по обеспечению сохранности грузов, а именно технические: ограждение территории парка или станции в целом; применения запорно-пломбировочных устройств (ЗПУ) с чипом; применение ЗПУ с GPS-навигацией для прослежиания нахождения вагонов и контейнеров в период доставки и с датчиком на разрыв с передачей данных; GPS-навигация вагонов для «on-line» отслеживания местонахождения вагонов и исключения возможостей их несанкционированного перемещения в пределах станции. Мероприятия по технологии осуществления охраны грузов, корректировке времени выхода работников ВОХР на смену с учетом ниток графика движения грузовых поездов; диспетчерский контроль за соблюдением графиков времени движения поезда по участку; анализ маршрутов следования грузовых поездов, выявление участков и перегонов железной дороги с повышенной криминогенной обстановкой и процедура установления альтернативных маршрутов с целью отклонения грузопотоков из этих участков; использование служебных собак в качестве вспомогательного средства при охране грузов или преследовании лиц.

По взаимодействию служб ВОХР с клиентами железных дорог предлагается: присутствие работника ВОХР при выполнении погрузки в крытый вагон на местах необщего пользования в целях личного наблюдения за процессом; требовать от отправителей фотографирования грузов после окончания загрузки и подкладывания фотографий с сопроводительными документами на груз; требовать от грузоотправителей нанесения слоя извести или сплошных полос краски на поверхности груза после окончания его загрузки в открытый подвижной состав и т. п.

Одним из ряда технических решений, которые рассматриваются, является система видеонаблюдения за подвижным составом и элементами инфраструктуры. Для стоимостной оценки ожидаемых (фактических) результатов будем использовать предпринимательский подход, который заключается в определении экономического эффекта отдельно получаемого разработчиком, производителем и потребителем нововведения. Маркетинговые исследования показали, что потребность в видеокамерах в парке длиной 1250 м одной станции составляет 8 единиц. По проведенным расчетам экономический эффект от внедрения видеонаблюдения на пятый год его эксплуатации составляет: пессимистичный 13884 грн.; средний - 40417 грн.; оптимистичный 66941 грн. Срок окупаемости данного мероприятия по оптимистичному прогнозу составляет 2 года.

Аналогично рассчитан экономический эффект от осуществления ограждения территории в парке станции, где размещают вагоны с грузами, находящимися под охраной. На пятый год эффект от его эксплуатации составит: пессимистичный 23560 грн.; средний - 12930 грн.; оптимистичный -
2360 грн. Срок окупаемости данного мероприятия по оптимистичному прогнозу составляет 6 лет при сроке эксплуатации более 20 лет.

Дополнительным элементом, позволяющим повысить качество технологии охраны грузов является установление на территории станции считывающих устройств RFID-системы для получения информации с RFID-меток, которые прилагаются к конструкции ЗПУ, с целью фиксации данных об их целостности или времени, когда их целостность была нарушена. Экономический эффект от внедрения RFID-системы на пятый год ее использования составляет: пессимистичный - 31880 грн.; средний 21270 грн.; оптимистичный - 10680 грн. Срок окупаемости данного мероприятия по оптимистическому прогнозу составляет 7 лет при сроке эксплуатации 10 лет.

\section{5. Апробация результатов исследований}

Наиболее значимыми потерями груза при перевозке можно условно считать сверхнормативные потери, возникшие по вине железной дороги, за исключением случаев действия обстоятельств непреодолимой силы (форс-мажор). Сверхнормативным является только количество потерянного (испорченного) груза, превышающее нормы естественной убыли.

Финансовые убытки возможно минимизировать, если грузовладелец имеет возможность заранее застраховаться от последствий сверхнормативных потерь при перевозке. Таким образом, задачу формально возможно рассмотреть как процесс управления страховыми рисками, независимо от того, кто будет субъектом ответственности за недостачу.

В формальной модели управления страховым риском несохранности при перевозке следует учитывать условия работы субъектов - страхователей и страховых компаний, а также условия конкуренции между страховыми компаниями, действующими на транспортном рынке.

Рассмотрим процесс страхования риска несохранных перевозок по железной дороге, когда в перевозке участвует $N$ видов грузов, в том числе принадлежащих разным грузовладельцам. Целевая функция, описывающая процесс, обусловлена ожидаемой полезностью, то есть суммой покрытия убытков у грузовладельца или у железной дороги в случае наступления страхового случая (несохранной перевозки груза)

$H^{*}=\sum_{i=1}^{N} H_{i}=\sum_{i=1}^{N}\left[\Pi r_{\mathrm{i}}-\mu_{i}+p_{i}\left(M_{i}-u_{\mathrm{i}}\right)\right] \rightarrow \max , \forall i \exists\left(M_{i} \geq 0, u_{\mathrm{i}} \geq 0\right),(1)$

где $\Pi r_{\mathrm{i}}$ - общая прибыль от реализации после перевозки і-го груза; $\mu_{i}-$ страховой взнос грузовладельца по і-му грузу, чаще всего страховщики устанавливают $\mu_{i}=k * \Pi_{r i}$, то есть как процент от планируемой прибыли; $p_{i}$ - вероятность наступления страхового случая (несохранной перевозки груза); $M_{i}$ - страховое возмещение; $u_{\mathrm{i}}-$ убытки от наступления страхового случая. 
В процессе перевозки страхование осуществляется на протяжении определенных периодов времени, в течение которых однократно выполняется сбор взносов $\mu_{\mathrm{i}}$ и компенсация возможных убытков $M_{i}$.

В условиях равного и недискриминационного доступа к транспортному рынку все грузовладельцы страхуются одинаково (k=const) и одинаково относятся к возможному риску несохранности. Однако в общем случае будет различной вероятность наступления страхового случая $p_{i}$, а значит - убытки $u_{\mathrm{i}}$. Таким образом, можно считать страховые случаи для разных грузов и у разных грузовладельцев потоком независимых событий. Основной эффект от страхования зависит от того, на каких условиях грузовладельцы застраховали вероятность несохранной перевозки. По этим условиям грузовладелец, железная дорога и страховщик могут иметь информацию друг от друга о риске возможной несохранности. При этом перераспределение такой информации может привести к неполной информированности или вовсе к отсутствию таковой, следовательно, возможно нарушение сбалансированности страховых взносов $\mu_{\mathrm{i}}$ и размеров компенсации убытков $M_{i}$.

В условиях полной информированности о возможности несохранности груза суммарный страховой взнос равен математическому ожиданию выплат

$$
\left[\sum_{i=1}^{N} \mu_{i}=\sum_{i=1}^{N} p_{i} M_{i}\right] \Rightarrow\left[p_{i} M_{i}-u_{i}\right]=0 .
$$

В рамках этого подхода страховой взнос каждого і-го грузовладельца в точности равен сумме возможного ущерба. В реальных условиях индивидуальные параметры перевозки в большей степени, чем другим участникам, известны только железной дороге. Это нарушает условие баланса (2), и ограничивает страховые выплаты $\mathrm{M}_{\mathrm{i}}$ пропорционально фактической оценке наступления страхового случая $\tilde{p}_{i}$, сообщаемой и часто сознательно заниженной со стороны железной дорогой, то есть $\tilde{p}_{i} \leq p_{i}$. Поскольку таким образом занижается и фактический уровень страховых выплат, можно считать, что ограничение на достоверную информацию о рисках несохранной перевозки уменьшает привлекательность и конкурентоспособность перевозчика на $1-\frac{\tilde{p}_{i}}{p_{i}}$.

\section{6. Выводы}

Проведены исследования обеспечения сохранности при перевозке железнодорожным транспортом. Их анализ указал на необходимость разработки современных подходов по качественной технологии охраны грузов. Предложены технические, технологические и организационные мероприятия по повышению сохранности грузов. Оценен экономический эффект некоторых мероприятий. Рассмотрены также правовые отношения железных дорог и грузовладельцев в аспекте несохранности перевозок. Представлена модель управления страховыми рисками несохранности при перевозке, что позволит минимизировать финансовые убытки от сверхнормативных потерь при перевозке.

\section{Литература}

1. У 2013 році зафіксовано рекордну кількість незаконних втручань у роботу залізничного транспорту [Електронний ресурс] / Режим доступу: http://uz.gov.ua/press_center/up_to_date_topic/372533/

Загол. $з$ екрану.

2. Офіційний веб-сайт Укрзалізниці. ПКО у забезпеченні безпеки руху [Електронний ресурс] / Режим доступу: http//www.uz.gov.ua

3. Ломотько, Д. В. Підвищення рівня схоронності вантажів, що перевозять по залізницях України [Текст] / Д. В. Ломотько, М. М. Кузнецов, О. М. Пилипейко. - Наука в транспортном измерении. - К.:ДНДЦ УЗ, 2006. -67 с.

4. Кузнецов, М. М. Забезпечення безпеки руху i схоронності вантажів на залізницях [Текст] / М. М. Кузнецов // Залізничний транспорт України. - 2005. - № 3/1. C. 19.

5. На Придніпровській залізниці збитки від не збережених перевезень вантажів торік зменшилися в 1,6 рази [Електронний ресурс] / Режим доступу: http://uz.gov.ua/press_center/latest_news/372585/ - Загол. 3 екрану.

6. Ограждения вдоль железнодорожного полотна установили на двух станциях в Удмуртии [Электронный pecypc] / Режим доступа: http://izvestiaur.ru/news/ view/6422501.html - Загол. з екрану.

7. Харін, М. Перевезення, небезпечні для вантажів [Електронний ресурс] / М. Харін. - Режим доступу: http//www.uz.gov.ua № 25-26.

8. Статут залізниць України / Магістраль, 1998. -

9. Правила размещения и крепления грузов в вагонах и контейнерах (Прил. 14 к СМГС) [Электронный pecypc] / Режим доступа: http://uz.gov.ua/cargo transportation/legal_documents/terms_o f_freight/page-2/264680/

10. Господарський кодекс України [Текст] / Прийнятий Верховною Радою України 16 січня 2003 року.

\section{References}

1. In 2013, registered a record number of illegal interference in rail transpor. Available at: http://uz.gov.ua/press_center/up_to_date_topic/ 372533/

2. FFP in ensuring traffic safety. Available at: http // www.uz.gov.ua

3. Lomotko, D., Kuznetsov, M., Pylypeyko, A. (2006). Improving the storage safety of cargo transported by railways of Ukraine. Science in transport measurement. Kiev: DNDTS UZ-2006, 67.

4. Kuznetsov, M. (2005). Ensuring the traffic safety and preservation of goods on railways. Railway Ukraine, 3/1, 19.

5. On the Dnieper railroads loss of unsaved carriage of goods last year decreased 1.6 time. Available at: http://uz.gov.ua/press_center/latest_news/372585/

6. Barriers near rail have installed on canvas in two stations of Udmurtia. Available at: http://izvestiaur.ru/news/ view/6422501.html

7. M. Kharin Transportation are hazardous to cargo. Available at: http//www.uz.gov.ua

8. Charter of Ukraine railways (1998). Highway, 25-26.

9. Rules for stowing and securing cargo in wagons and containers (App. 14 to SMGS). Available at: 
http://uz.gov.ua/cargo transportation/legal_documents/terms_o f_freight/page-2/264680/
10. Economic Code of Ukraine (2003). The Verkhovna Rada of Ukraine on 16 January 2003.

Дата надходження рукопису 25.11.2014

Ломотько Денис Викторович, доктор технических наук, профессор, кафедра транспортные системы и логистики, Украинская государственная академия железнодорожного транспорта, пл. Фейербаха, 7, г. Харьков, Украина, 61050

E-mail: den@kart.edu.ua

Запара Ярослав Викторович, кандидат технических наук, доцент, кафедра управление грузовой и коммерческой работы, Украинская государственная академия железнодорожного транспорта, пл. Феербаха, 7, г. Харьков, Украина, 61050

E-mail: y.zapara@gmail.com

Лютый Виталий Анатольевич, кандидат технических наук, доцент, кафедра строительные материалы, конструкции и сооружения, Украинская государственная академия железнодорожного транспорта, пл. Фейербаха, 7, г. Харьков, Украина, 61050

E-mail: 2010lva@rambler.ru

\title{
УДК 629.4.053.3; 629.424.1.192
}

DOI: $10.15587 / 2313-8416.2014 .31997$

\section{МЕТОД ВИЗНАЧЕННЯ ТЕХНІЧНОГО СТАНУ ТЕПЛОВОЗУ В УМОВАХ ЕКСПЛУАТАЦІї}

\author{
(C) Р. В. Турчинов, С. О. Змій \\ На даний час контроль технічного стану тепловозу можливо виконати тільки в умовах депо. \\ Представлений метод дозволяє встановити технічний стану тепловозу в умовах безпосередньої \\ експлуатації. На основі оперативних даних про динаміку зміни параметрів, щзо контролюються, \\ приймається рішення, щуодо формування множини робіт з обслуговування та ремонту
}

Ключові слова: технічний контроль, стан тепловоза, тягова характеристика, діагностика, оперативний контроль

The control of technical condition of locomotive currently may perform only in train shed. This method allows setting the technical condition of locomotive in terms of direct operation. It is made a decision on forming of maintenance and repair works based on available data on the dynamics of parameters that are controlled

Keywords: technical control, locomotive condition, traction characteristics, diagnosis, operative control

\section{1. Вступ}

Економічна ефективність залізничного транспорту складається 3 багатьох факторів, одним 3 яких $\epsilon$ вартість тепловозного парку 3 урахуванням всього життєвого циклу. Головним етапом життєвого циклу $\epsilon$ період експлуатації. Для підтримки тепловозного парку в належному технічному стані в теперішній час використовується плановопопереджувальна система технічного обслуговування, яка не враховує технічний стан окремого тепловозу [1-3]. Перспективним напрямком є перехід до планово-діагностичної системи технічного обслуговування, в якій особливу увагу приділяють тим засобам та методам контролю технічного стану, що не потребують виконання додаткових робіт. До таких засобів відносяться бортові системи моніторингу та діагностування.

\section{2. Постановка проблеми}

Більшість робіт по визначенню технічного стану тепловозу проводиться в умовах депо, потребують додаткових матеріальних та людських витрат. На даний час для отримання основних характеристик тепловозу потрібно проведення додаткових випробувань 3 використанням динамометричного вагону, що використовується при планово-попереджувальних роботах [1].

Перехід до планово-діагностичної системи технічного обслуговування потребує використання сучасних систем діагностики рухомого складу, які в змозі проводити поточну обробку інформації для побудови основних характеристик безпосередньо в умовах експлуатації без застосування додаткових витрат.

\section{3. Літературний огляд}

Проблемі технічної діагностики та прогнозування стану систем присвячено достатньо велика кількість робіт. Розробки [4-6] направлено на створення систем дистанційного контролю параметрів рухомого складу. Однак такі системи мають можливість оцінки тільки зовнішніх параметрів i не мають змогу оцінити внутрішні параметри, що обумовлюють технічний стан.

Інша категорія розробок була направлена на розробку систем, що здійснюють запис одного або декількох параметрів 3 подальшою обробкою на робочих місцях. Такий спосіб хоч i надає більш 